\title{
EDITORIAL
}

\section{Indigenous Rights Amidst Global Turmoil}

\section{INTRODUCTION}

The year 2020 cannot end quickly enough. We enter the final quarter of a year in which cataclysmic fires erupted across Australia and the United States (US) west coast, devastating floods swept across Sudan, a pandemic ravages the lives of millions while bringing the global economy to a virtual standstill, and acts of profound injustice have acted as a startling reminder of the systemic racism that pervades American society as well as others around the world. Environmental concerns are deeply interwoven with each of these storylines. In many respects 2020 represents a glimpse into the future that climate science has warned us about for decades. The risk of intensified fires and floods has long been a major theme of such warnings. Epidemiologists have cautioned that infectious diseases may spread faster and further in a warmer world. ${ }^{1}$ Also, social unrest, with its invariably racist inflections, will no doubt result from climate migration, from strains on global food supply, from water insecurity, and from the multitude of other ways in which environmental change and climate change expose and exacerbate existing social and ecological vulnerabilities.

A persistent theme in the pages of Transnational Environmental Law (TEL) is that environmental law and policy cannot and should not be divorced from broader humanist concerns and objectives. To say so is not to recess into anthropocentrism, but rather to affirm that humanity's depredations of the planet's ecological systems are so pervasive that no aspect of social organization can, or should, ignore them any longer. Environmental law ought never again be regarded as a mere niche. Environmental awareness is not a luxury; it is a staple of social progress. Environmental degradation threatens culture; it endangers the economy; it perpetuates injustice; and it deprives our children of the opportunity to flourish. Now, more than ever, students of environmental law and policy must bring their knowledge, skills, and values to bear on the extraordinary and multifaceted problems that confront us on every side.

Nowhere is the integration of environmental and broader social concerns more necessary than in those contexts in which Indigenous populations are forced to confront state authority for basic environmental welfare. In countless instances, global

1 See, e.g., S. Altizer et al., 'Climate Change and Infectious Diseases: From Evidence to a Predictive Framework' (2013) 341(6145) Science, pp. 514-9. See also P.L. Farnese, 'The Prevention Imperative: International Health and Environmental Governance Responses to Emerging Zoonotic Diseases' (2014) 3(2) Transnational Environmental Law, p. 285-309. 
economic development has inflicted environmental harm first and foremost on Indigenous peoples. Industrial growth, of both the western and eastern varieties, has created legal orders that (quite literally) pave the way for yet more industrial growth, erecting jurisprudential doctrines that ratify and justify economic ambitions while systematically excluding Indigenous voices. These voices, if allowed to speak, tell of ancient ancestral connections with places and natural features. They teach of nature's truths, patiently acquired across generations of direct connection with the land. For law to accomplish justice among Indigenous societies, it must listen to and internalize such voices, and wield its power to protect both person and place.

The present issue of TEL focuses its attention almost entirely on transnational issues of Indigenous rights. At the heart of the issue is an expansive Symposium collection exploring Indigenous water rights from a comparative perspective. The Symposium, which collects papers delivered at a recent event at the University of Canterbury School of Law in Christchurch (New Zealand), consists of six papers. They have in common their interdisciplinary approach and their detailed, grounded exploration of various local disputes over water access and use. These disputes, we learn, are not boutique environmental matters, but matters which cut to the heart of Indigenous peoples' very right to exist and to sustain themselves as they have for millennia. The Symposium collection is followed by two stand-alone articles, one of which addresses the rights of nature as it has arisen in Indigenous contexts, and the other examines the law of soil pollution in China.

\section{SYMPOSIUM COLLECTION ON INDIGENOUS WATER RIGHTS}

The Symposium collection employs interdisciplinary analysis from a comparative perspective. Capably introduced in a separate Symposium Foreword by Elizabeth Macpherson, ${ }^{2}$ herself one of the leading contributors, the collection features six separate articles that span the Pacific Ocean in their geographic focus. From New Zealand to Chile and back to Australia, the authors share an interest in the articulation and development of water rights for Indigenous peoples against the common backdrop of western laws that still inadequately recognize them. As Macpherson describes, the Symposium articles examine issues of jurisdiction - the recognition of Indigenous rights amidst ill-fitting, externally imposed legal regimes - and distribution - the substantive provision of rights to water.

On both the jurisdictional and distributional fronts, these articles provide a decidedly mixed account of the state of affairs. To be sure, there are threads of optimism: the reader will learn of successful efforts at river co-management, ${ }^{3}$ and of encouraging trends towards more thorough recognition of Indigenous customs and

2 See E. Macpherson, 'Symposium Foreword: Indigenous Water Rights in Comparative Law' (2020) 9(3) Transnational Environmental Law, pp. 393-402.

3 See K. Fisher \& M. Parsons, 'River Co-governance and Co-management in Aotearoa New Zealand: Enabling Indigenous Ways of Knowing and Being' (2020) 9(3) Transnational Environmental Law, pp. $455-80$. 
cultures. ${ }^{4}$ There are also the inevitable reminders that, with disturbing regularity, Indigenous claims are excluded and obscured even by legal interventions designed to enhance their visibility. ${ }^{5}$ Importantly, the Symposium's diverse accounts make obvious that Indigenous cultures differ from each other as much as they are alike, and that genuine intercultural engagement, especially within legal structures, can never be a simple cut-and-paste task across disparate contexts. ${ }^{6}$ A deep, enduring, and decolonialized justice will prevail only when each domestic (water) law regime confronts its own exclusionary pathologies.

One particularly "fitting embodiment of the Symposium themes" can be found in the byline of the final Symposium article, in which we see the ancestral Martuwarra River from the far northwestern corner of Australia - itself listed as the lead author. ${ }^{8}$ A word of welcome from the river opens the article and sets the reader on a fascinating and frustrating exposition of the various, intertwined impediments to recognition of native title water rights. The depth and detail of this contribution are characteristic of the full Symposium and testify to the salutary scholarly attention devoted to this important area of work and concern.

\section{RIGHTS OF NATURE WITHIN AND WITHOUT INDIGENOUS CULTURES}

Laura Schimmöller's article follows neatly after the Symposium collection in its attention to the rights of nature as a novel legal formulation. ${ }^{9}$ A handful of other recent articles in TEL have critically examined the recent turn towards the establishment of legal rights for non-human natural entities. ${ }^{10}$ Building on this work, Schimmöller asks

4 See E. O’Donnell, A. Poelina, A. Pelizzon \& C. Clark, 'Stop Burying the Lede: The Essential Role of Indigenous Law(s) in Creating Rights of Nature' (2020) 9(3) Transnational Environmental Law, pp. 403-27.

5 See M. Tănăsescu, 'Rights of Nature, Legal Personality, and Indigenous Philosophies' (2020) 9(3) Transnational Environmental Law, pp. 429-53; E. Macpherson, J. Torres Ventura \& F. Clavijo Ospina, 'Constitutional Law, Ecosystems, and Indigenous Peoples in Colombia: Biocultural Rights and Legal Subjects’ (2020) 9(3) Transnational Environmental Law, pp. 521-40.

6 Cf. Fisher \& Parsons, n. 3 above, with E.J. Macpherson \& P. Weber Salazar, 'Towards a Holistic Environmental Flow Regime in Chile: Providing for Ecosystem Health and Indigenous Rights' (2020) 9(3) Transnational Environmental Law, pp. 481-519.

7 Macpherson, n. 2 above, p. 396.

8 Martuwarra RiverOfLife, A. Poelina, D. Bagnall \& M. Lim, 'Recognizing the Martuwarra's First Law Right to Life as a Living Ancestral Being' (2020) 9(3) Transnational Environmental Law, pp. 541-68.

9 L. Schimmöller, 'Paving the Way for Rights of Nature in Germany: Lessons Learnt from Legal Reform in New Zealand and Ecuador' (2020) 9(3) Transnational Environmental Law, pp. 569-92.

10 P. Villavicencio Calzadilla \& L.J. Kotzé, 'Living in Harmony with Nature? A Critical Appraisal of the Rights of Mother Earth in Bolivia' (2018) 7(3) Transnational Environmental Law, pp. 397-424; L.J. Kotzé \& P. Villavicencio Calzadilla, 'Somewhere between Rhetoric and Reality: Environmental Constitutionalism and the Rights of Nature in Ecuador' (2017) 6(3) Transnational Environmental Law, pp. 401-33, A. Staker, 'Should Chimpanzees Have Standing? The Case for Pursuing Legal Personhood for Non-Human Animals' (2017) 6(3) Transnational Environmental Law, pp. 485-507; S. Borràs, 'New Transitions from Human Rights to the Environment to the Rights of Nature' (2016) 5(1) Transnational Environmental Law, pp. 113-43. 
whether granting rights to nature might prove an effective approach in Germany, a civil law country without a significant Indigenous population. Her principal points of reference are New Zealand, which through legislation has established legal personhood for two ecosystems since 2014, and Ecuador, where a constitutional amendment in 2008 enshrined protection for the 'rights of Mother Earth'. Unsurprisingly, neither country matches perfectly the particular legal, political, and cultural makeup of Germany, yet Schimmöller draws encouragement from their recent experiences all the same.

Although the concept of the rights of nature has attracted significant attention from environmentalists, Schimmöller observes that the legal enactments that create such rights '[a]t first sight ... might not resemble a reform that is directly related to environmental law'. ${ }^{11}$ Instead, these efforts are principally 'attempt[s] to codify Indigenous perspectives into modern legal frameworks' ${ }^{12}$ In New Zealand, legislation granting rights to the Te Urewera area (in 2014) ${ }^{13}$ and the Whanganui River (in 2017) ${ }^{14}$ represents the latest efforts to resolve long-standing land management disputes between Māori tribes and the Crown. ${ }^{15}$ In creating legal guardians for these ecosystems, the legislature integrated customary Māori language, values, and concepts to recentre the management process along lines more responsive to historical Indigenous claims. The law does not spell out 'much of the content of the rights and duties granted to nature' because its aim was rather to refashion the model for tribal cooperation with the Crown. ${ }^{16}$ Ecuador's constitutional provisions that address the rights of Mother Earth also draw heavily on Indigenous traditions. Quechuan terms are employed without translation, and the concept of a harmonious relationship between humans and nature, prevalent within Andean Indigenous populations, is central in the Constitution's preamble and environmental provisions. ${ }^{17}$

Schimmöller points out that these two countries were not identical in their approach. The Ecuadorian Constitution explicitly allows any person to demand public authorities to apply rights of nature, while ' $\mathrm{t}]$ he narrow approach in New Zealand, aimed at recognizing Māori responsibilities for their land, arguably has less of a focus on nature's rights in themselves'. ${ }^{18}$ It is undoubtedly too soon to draw firm conclusions about the merits of each strategy, let alone the efficacy of rights of nature as a general matter. Legal reform is a social process, and although these particular reforms herald a sea change in environmental jurisprudence, they will no doubt engender opposition. Success or failure will depend largely on the vigour with which litigants assert the newly created rights, the legislatures develop them, and the courts endorse and apply them. The Ecuadorian courts, for example, have needed 'education' to clarify 'newly found norms in court'. ${ }^{19}$

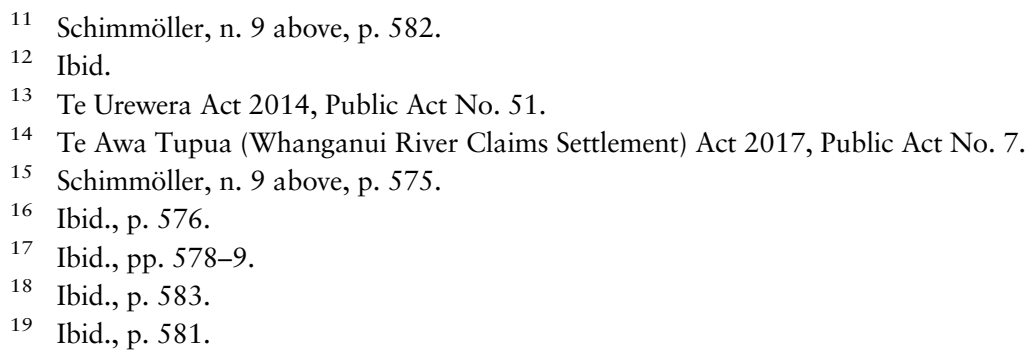


Could rights of nature take root in German soil? There are boulders in the field, but Schimmöller finds cause for optimism. The jurisprudential obstacles have to do primarily with the doctrine of standing. Germany's public interest litigation model already allows certain recognized environmental organizations to access the courts, leading some analysts to conclude that a rights of nature approach in terms of practical enforcement ... would in practice create no significant difference compared with the existing model'. ${ }^{20}$ Moreover, the cultural landscape lacks the Indigenous and spiritual elements that have significantly informed rights-based approaches elsewhere. Nonetheless, Schimmöller argues that the move from human duties to nature's rights could powerfully influence German environmental thought and 'reshape the legal and moral conceptions of the environment' ${ }^{21}$ It remains to be seen, of course, which direction environmental advocates pursue in German courts, but we are confident that this article will prove an important contribution to the debate.

\section{LAND AND (RETROACTIVE) LIABILITY}

The final contribution to this TEL issue comes from Huanhuan Wang, whose article turns away from Indigenous issues and rights of nature and instead calls attention to the expanding reach of soil remediation schemes in Southeast Asia. ${ }^{22}$ Focusing on the law of China, Wang's particular emphasis is the retroactive application of such schemes. The imposition of retroactive liability is perennially fraught, both jurisprudentially and politically, and especially so when the conduct at issue occurred both before the enactment of the clean-up law and in full compliance with pre-existing rules. Such instances place the polluter-pays principle, a cornerstone of environmental law, squarely at odds with the stability and reliance interests long understood to be central to the rule of law.

Wang's article navigates its way delicately through these shoals. The author begins with a cautious justification for retroactive liability in the context of contaminated soil. Soil pollution is an enduring environmental problem of the first magnitude. China's need for a strong remedial programme is pronounced, given its rapid industrialization in recent years. Liability schemes, Wang argues, serve the public interest by identifying the parties responsible for pollution and placing the burden of clean-up on their shoulders, rather than with the general public or present landowners. Wang appreciates the reliance interests of liable parties, but argues that arguments based on reliance are 'all too often questionable'. ${ }^{23}$ '[L]iability for cleaning up contaminated land is, to varying degrees, foreseeable for potentially liable parties', and all the more in an era in which those parties can be charged with the expectation that environmental standards

20 Ibid., p. 588.

21 Ibid.

22 H. Wang, 'Retroactive Liability in China's Soil Pollution Law: Lessons from Theoretical and Comparative Analysis' (2020) 9(3) Transnational Environmental Law, pp. 593-616. Cf. Y. Yoon, 'The Impacts and Implications of CERCLA on the Soil Environmental Conservation Act of the Republic of Korea' (2017) 6(1) Transnational Environmental Law, pp. 11-29.

23 Wang, ibid., p. 597. 
will become more rigorous over time. ${ }^{24}$ To forbear retroactive liability would be to allow the 'historically responsible party' to benefit from pollution, despite the fact that 'most liable parties are relatively more economically powerful than those who are injured'. ${ }^{25}$

Canvassing the state of the law relating to retroactive liability around the world, Wang finds that 'almost all countries have either adopted, or tacitly approve of, retroactive liability for land contamination'. ${ }^{26}$ She notes, firstly, that retroactivity is often implicit rather than explicit in soil pollution law. In the United States, for example, the Comprehensive Environmental Response, Compensation, and Liability Act of 1980 (CERCLA or, more colloquially, the Superfund statute) ${ }^{27}$ is silent on its face as to retroactive application, but judicial exposition of the statute has clarified that liability is strict, joint and several, irrespective of the time of contamination and the state of the law at that time. The example is notable because CERCLA has served as a model for legislation worldwide. ${ }^{28}$ Secondly, Wang explains that soil remediation laws vary in their assignment of retroactive liability, with some schemes imposing retroactive liability only on those actually responsible for contamination and not on property owners. This distinction tracks the diminished culpability of owners whose liability would arise only 'from the social responsibility of their land entitlement'. ${ }^{29}$ Finally, some systems place an explicit temporal limitation on retroactive liability. This can be accomplished either by exempting soil contamination caused by activities before a particular date, or by specifying a limitation period beyond which liability may no longer be assigned. ${ }^{30}$

Relying on this survey, Wang draws several lessons for China's 2018 Law on the Prevention and Control of Soil Pollution (Soil Pollution Law). ${ }^{31}$ She notes, firstly, that the ex ante risk management provisions of the law are inadequate to incentivize adequate land-use protection. As for retroactivity, she argues for a moderate approach, noting that China differs from other countries in its 'greater reliance on public finance', which reduces the need for absolute retroactivity. ${ }^{32}$ Nonetheless, the Soil Pollution Law 'should be worded more precisely', ${ }^{33}$ and 'clear temporal phases should be delineated in the regulations ${ }^{34}$ in order to reduce the liability of those entities whose pollution predated environmental regulation or was connected with state-owned enterprise.

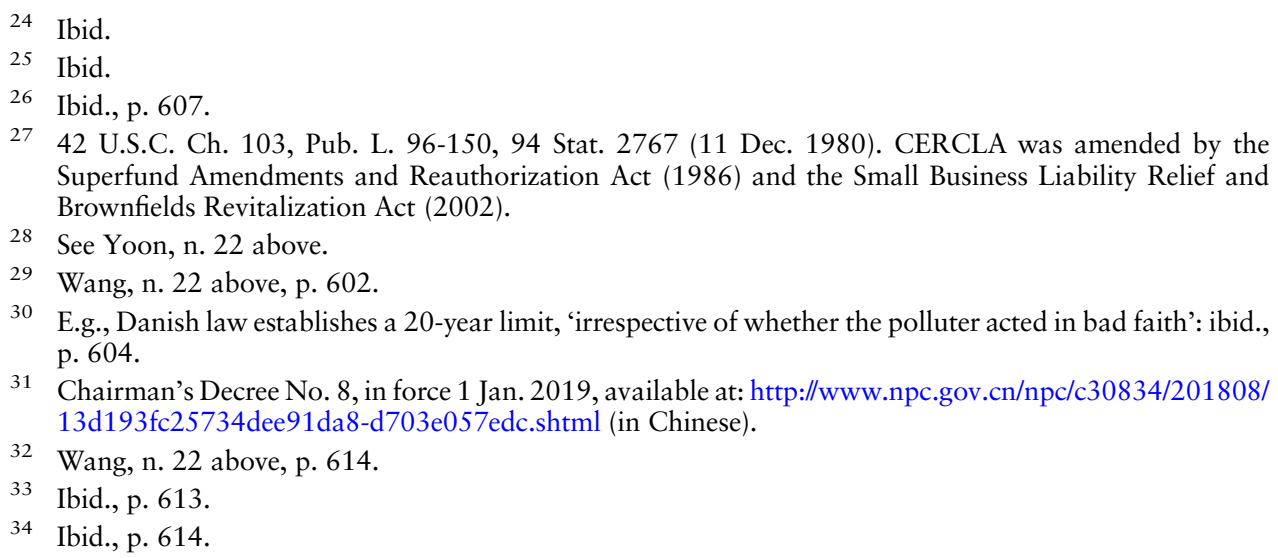




\section{TEL EDITORIAL BOARD DEVELOPMENTS}

There have been a few high notes for TEL during this year, which are worth reporting here.

We were delighted with the further increase in TEL's Impact Factor to 2.641 for 2018-19 (five-year Impact Factor of 2.205), according to the 2019 Journal Citation Reports of Clarivate Analytics. With this new Impact Factor, TEL has once again consolidated its position among the top three highest ranked environmental law journals worldwide, in both the law journals and environmental studies journals categories. This continued positive trend for TEL in these and other citation index rankings and usage metrics is a wonderful compliment and motivation for the entire TEL team, as well as our referees and certainly our contributors.

Last but certainly not least, it is with great pleasure that we welcome Sroyon Mukherjee of the WB National University of Juridical Sciences (India) to the team of TEL's Assistant Editors.

\section{FINAL REMARKS}

We end on a personal note. We wish to express our sincere hope that this issue of TEL finds you, our readers, in safety, health, and peace, and we wish to join you in the hope not only for a timely end to the current pandemic, but also for a better, more just tomorrow. We are grateful for your support during this difficult year and grateful, too, for the community of authors and reviewers who are the lifeblood of this journal. Your work is meaningful and important, and we are privileged to support it, particularly during these challenging times.

Editors-in-Chief

Thijs Etty

Veerle Heyvaert

Editors

Cinnamon Carlarne

Bruce Huber

Jacqueline Peel

Josephine van Zeben 